Int. J. Electrochem. Sci., 13 (2018) $8931-8943$

\title{
Amperometric Assay of Sodium Dodecyl Sulfate Based on Anion Exchange Using PDDA as Active Acceptor
}

\author{
Zhong-Xia Wang, Yuan-Fei Gao, Xian-He Yu, Fen-Ying Kong, Wen-Juan Wang, \\ Wei-Xin Lv and Wei Wang * \\ School of Chemistry and Chemical Engineering, Yancheng Institute of Technology, Yancheng \\ 224051, China. \\ *E-mail: wangw@ycit.edu.cn
}

doi: $10.20964 / 2018.09 .39$

Received: 12 May 2018 / Accepted: 13 June 2018 / Published: 5 August 2018

This study demonstrates a facile and effective strategy for amperometric assay of electrochemically inactive sodium dodecyl sulfate (SDS) based on different binding affinity of poly(diallyldimethylammonium chloride) (PDDA) toward electrochemically inactive SDS and active $\left[\mathrm{Fe}(\mathrm{CN})_{6}\right]^{3-/ 4-}$ anions. To improve conductivity of the modified electrode nanomaterial, PDDA/GO/SWCNTs hybrid nanomaterial is first prepared and used as the artificial receptor to recognize the anions (i.e., $\left[\mathrm{Fe}(\mathrm{CN})_{6}\right]^{3-4-}$ and SDS). The stronger binding affinity of the PDDA toward SDS than $\left[\mathrm{Fe}(\mathrm{CN})_{6}\right]^{3-/ 4-}$ anions results in the decrease of the redox peaks current of surface modified PDDA and provides a quantitative signal readout for the SDS assay. Thereafter, an amperometric assay for SDS based on anion-exchange at $\left[\mathrm{Fe}(\mathrm{CN})_{6}\right]^{3-/ 4-/ P D D A} / \mathrm{GO} / \mathrm{SWCNT}$ modified glassy carbon electrode was developed. The ratio of the current decrease shows a linear relationship with SDS concentration range from 1.0 to $200 \mu \mathrm{M}$, and the limit of detection of SDS is $36.51 \mathrm{nM}$. And the results indicate that the study not only provides a simple and effective way to a polyanion of SDS assay, but also opens a new route to developing electrochemical methods for electrochemically inert contaminants by fully utilizing the anion-exchange principles.

Keywords: Poly(diallyldimethylammonium chloride); Differential pulse voltammograms; Electrochemically inactive; Anion-exchange; Sodium dodecyl sulfate;

\section{FULL TEXT}

(C) 2018 The Authors. Published by ESG (www.electrochemsci.org). This article is an open access article distributed under the terms and conditions of the Creative Commons Attribution license (http://creativecommons.org/licenses/by/4.0/). 